\title{
Pediatric multisystem inflammatory syndrome associated with COVID-19: urgent attention required
}

\author{
Carlos Alberto Nogueira-de-Almeida1* (1), Luiz Antonio Del Ciampo² (D), Ivan Savioli Ferraz² (1), \\ leda Regina Lopes Del Ciampo ${ }^{1}$ (), Andrea Aparecida Contini' (1), Fábio da Veiga Ued ${ }^{3}$
}

\section{SUMMARY}

OBJECTIVE: To identify epidemiological and clinical characteristics of multisystemic inflammatory syndrome associated with coronavirus infection as one of the severe forms of COVID-19 involvement in children and adolescents.

METHODS: review was based on articles published in 2020 in the PubMed, Medline, Scopus, SciELO and Cochrane databases.

SUMMARY: Multisystemic inflammatory syndrome is a serious clinical disorder that affects children and adolescents and is associated with the detection of previous exposure to SARS-CoV-2. It is characterized by the installation of a shock picture, with a significant increase in inflammatory markers such as presentations of Kawasaki Disease or shock syndrome related to Kawasaki Disease, or even toxic shock syndrome, with the clinical picture being characterized by fever of difficult control, rash, conjunctivitis, peripheral edema, generalized pain in the extremities and gastrointestinal symptoms.

CONCLUSIONS: Although the vast majority of children with COVID-19 have mild symptoms, it is necessary to consider that some have a hyperinflammatory response. It is essential that health professionals receive information that can assist in the recognition of this clinical condition, differentiating it from other diagnoses, so that early and appropriate treatment is instituted.

KEYWORDS: Betacoronavirus. Coronavirus infections. Child. Systemic inflammatory response syndrome. Mucocutaneous lymph node syndrome.

\section{INTRODUCTION}

The first case of a disease with significant pulmonary impairment caused by a new species of coronavirus (SARS-CoV-2) was reported In China, in December 2019. Due to its high transmissibility, it was quickly declared a pandemic, responsible for more than 19 million confirmed cases and over 728,000 deaths worldwide by August $10^{\text {th }}, 2020^{1}$. Its incidence among children and adolescents can reach $5 \%$ of all cases $^{2}$ and mortality is probably low ${ }^{3}$, but children under one year of age are more likely to have complications of the disease ${ }^{4}$. Obese children are also at risk for serious manifestations ${ }^{5}$, including higher risk of multisystem inflammatory syndrome $e^{6}$.
On the other hand, adults with comorbidities and older adults represent the main risk groups; the majority of affected children and adolescents are asymptomatic or have mild airway infection or gastrointestinal symptoms, abdominal pain, vomiting, and diarrhea ${ }^{7}$. However, in view of clinical peculiarities manifested during the evolution of some cases, a group of children who had severe forms of a systemic inflammatory disease could be identified, similar to Kawasaki Disease (KD), which was called multisystemic inflammatory syndrome in children (MIS-C) due to coronavirus infection ${ }^{8}$. KD is a febrile and acute vasculitis that affects young children, primarily not belonging to any specific risk group?. Given this syndrome does not yet have adequately defined etiological factors, it

\footnotetext{
'Universidade Federal de São Carlos, Medicine Department - São Carlos (SP), Brazil.

¿Universidade de São Paulo, Faculdade de Medicina de Ribeirão Preto, Medical School of Ribeirão Preto, Departament of Childcare and Pediatrics São Paulo (SP), Brazil.

${ }^{3}$ Universidade de São Paulo, Medical School of Ribeirão Preto, Department of Health Sciences- Ribeirão Preto (SP), Brazil.

*Corresponding author: dr.nogueira@me.com

Conflicts of interest: the authors declare there are no conflicts of interest. Funding: none.

Received on September 22, 2020. Accepted on October 21, 2020.
} 
becomes even more challenging to understand its overlapping with MIS-C ${ }^{10-12}$ and its relation with COVID-19, as well as its causes and prognosis, which are still being better studied. Due to its severity, different scientific societies have sought to create criteria for defining cases and treatment, and alert health professionals about the disease ${ }^{13-16}$.

This article seeks to review current knowledge about MIS$\mathrm{C}$, with the main objective of providing health professionals with the necessary knowledge so that they can make the diagnosis and implement the treatment of this condition in face of the COVID-19 pandemic.

\section{MULTISYSTEMIC INFLAMMATORY SYNDROME IN CHILDREN ASSOCIATED WITH SARS-COV-2 (MIS-C)}

\section{Case series}

MIS-C refers to a new and serious clinical disorder, first described in April 2020 by Riphagen et al. ${ }^{17}$, affecting previously healthy children. They studied eight cases in England, and all patients evolved with circulatory shock refractory to volumetric expansion, requiring use of vasoactive drugs for hemodynamic support; pleural, pericardial effusions and ascites were common findings; ventricular dysfunctions were observed in most patients, and an eight-year-old child developed significant coronary dilation. Most children did not have significant respiratory involvement, although ventilatory support was required in seven (87.5\%) of the eight patients. An obese 14-year-old patient died, secondary to extensive cerebral infarction. During hospitalization, everyone tested negative for SARS-CoV-2 in bronchoalveolar lavage or nasopharyngeal aspirates. However, four children had previously known family exposure to COVID- $19^{17}$.

After this initial report, others were published. In an American series with 186 children and adolescents under 21 years of age (mean 8.3 years) with MIS-C, $70 \%$ of the individuals were positive for SARS-CoV-2 (RT-PCR or antibodies); $40 \%$ had symptoms that met the criteria for $\mathrm{KD}$, and $15 \%$, coronary aneurysms. A total of $92 \%$ had a significant increase in at least four inflammation markers, and four patients died ${ }^{8}$. In another series, $90 \%$ of 21 patients under 18 years of age (mean 7.9 years) with MIS-C treated at a hospital in Paris, presented evidence of infection by SARS-CoV-2; 57\% manifested signs and symptoms of shock syndrome associated with $\mathrm{KD}$, and $76 \%$, myocarditis. No patient died, but $24 \%$ had coronary dilation and significant increase in inflammation mark$\mathrm{ers}^{18}$. Among individuals in whom the presence of previous symptoms related to COVID-19 could be identified, the time interval between the onset of those symptoms and the onset of MIS-C was 25 days in American and 45 days in French series.

As to the features of the case series already described, some conclusions can be drawn: the syndrome has been manifested in children and adolescents about four weeks after contact with SARS-CoV-2. It appears to affect patients aged between four and 14 years old and is associated with detection of previous exposure to SARS-CoV-2. Children present with shock and increase in inflammatory markers, as seen in $\mathrm{KD}^{17}$, however, the age range in the MIS-C seems to be more advanced (average age of 10 years compared to two years for $\mathrm{KD}$ ) and respiratory, gastrointestinal and neurological symptoms are more frequent ${ }^{19}$. The clinical condition of MIS-C can be characterized by difficulty to control fever, rash, conjunctivitis, peripheral edema, generalized pain in the extremities, and gastrointestinal symptoms ${ }^{17}$. Affected children show marked lymphopenia and thrombocytopenia, coagulopathy, increased cardiac enzymes (troponin and cerebral natriuretic peptide, brain natriuretic peptide), hyponatremia, hypoalbuminemia, and increased serum lactate dehydrogenase and ferritin ${ }^{20}$.

\section{Diagnostic criteria and classification}

Recently, the American Centers for Disease Control and Prevention (CDC) proposed a criteria for screening MIS-C, which has been adopted in the United States to notify new cases (Figure 1). They also suggested a classification into three classes (Figure 2), aiming to better identify the most common presentations of the disease ${ }^{6}$. Both definitions were based on a series of 570 patients diagnosed with MIS-C in 40 states in the U.S., between March 2 and July 18, 2020. These patients had median age of eight years, $55.4 \%$ were male, and $40 \%$ were Hispanic/Latino. Two thirds were previous healthy, and $25.6 \%$ were obese. Regarding organ system, $86 \%$ had four or more involved. The majority were admitted at intensive care units (63.9\%) and had severe complications: cardiac dysfunction $(40.6 \%)$, shock (35.4\%), myocarditis (22.8\%), coronary artery dilatation or aneurysm (18.6\%), and acute kidney injury $(18.4 \%)^{6}$. The World Health Organization (WHO) ${ }^{21}$ also proposed a diagnostic criteria for preliminary case definition of MIS-C (Figure 1).

These CDC data also show that $99 \%(\mathrm{n}=565)$ of confirmed MIS-C cases in the United States tested positive for SARS$\mathrm{CoV}-2^{22}$. Although available data suggest that MIS-C is an uncommon complication of SARS-CoV-2 infection in children and adolescents ${ }^{8}$, current evidence does not support the conclusion that SARS-CoV-2 infection is the cause of MIS-C, with only a temporal relation being established. It should be noted that some cases may have a different underlying cause, such as toxic shock associated with other viruses ${ }^{23,24}$. In addition, 


\section{Case definition according to CDC}

- Less than 21 years old

- Fever $\geq 38.0^{\circ} \mathrm{C}$ for $\geq 24$ hours, or report of subjective fever lasting $\geq 24$ hours

- Laboratory evidence of inflammation including, but not limited to, one or more of the following:

elevated C-reactive protein, erythrocyte sedimentation rate, fibrinogen, procalcitonin, $d$ dimer, ferritin, lactic acid dehydrogenase, or interleukin 6, elevated neutrophils, reduced lymphocytes and low albumin

- No alternative plausible diagnoses

- Positive for current or recent SARS-CoV-2 infection by RT-PCR, serology, or antigen test; or exposure to a suspected or confirmed COVID-19 case within the 4 weeks prior to the onset of symptoms

\section{Case definition according to WHO}

- Children and adolescents $0-19$ years of age

- Fever $>3$ days

- AND two of the following:

a) Rash or bilateral non-purulent conjunctivitis or mucocutaneous inflammation signs (oral, hands or feet) b) Hypotension or shock

c) Features of myocardial dysfunction, pericarditis, valvulitis, or coronary abnormalities (including ECHO findings or elevated Troponin/NT-proBNP)

d) Acute gastrointestinal problems (diarrhoea, vomiting, or abdominal pain)

e) Evidence of coagulopathy (by PT, PTT, elevated d-Dimers)

- AND

f) Elevated markers of inflammation such as ESR, C-reactive protein, or procalcitonin

- AND

g) No other obvious microbial cause of inflammation, including bacterial sepsis, staphylococcal or streptococcal shock syndromes

- $\quad$ AND

h) Evidence of COVID-19 (RT-PCR, antigen test or serology positive), or likely contact with patients with COVID-19

MIS-C: multisystemic inflammatory syndrome in children; CDC: centers for disease control; WHO: World Health Organization.

Figure 1. Case definition for multisystemic inflammatory syndrome in children, according to the centers for disease control and the World Health Organization.

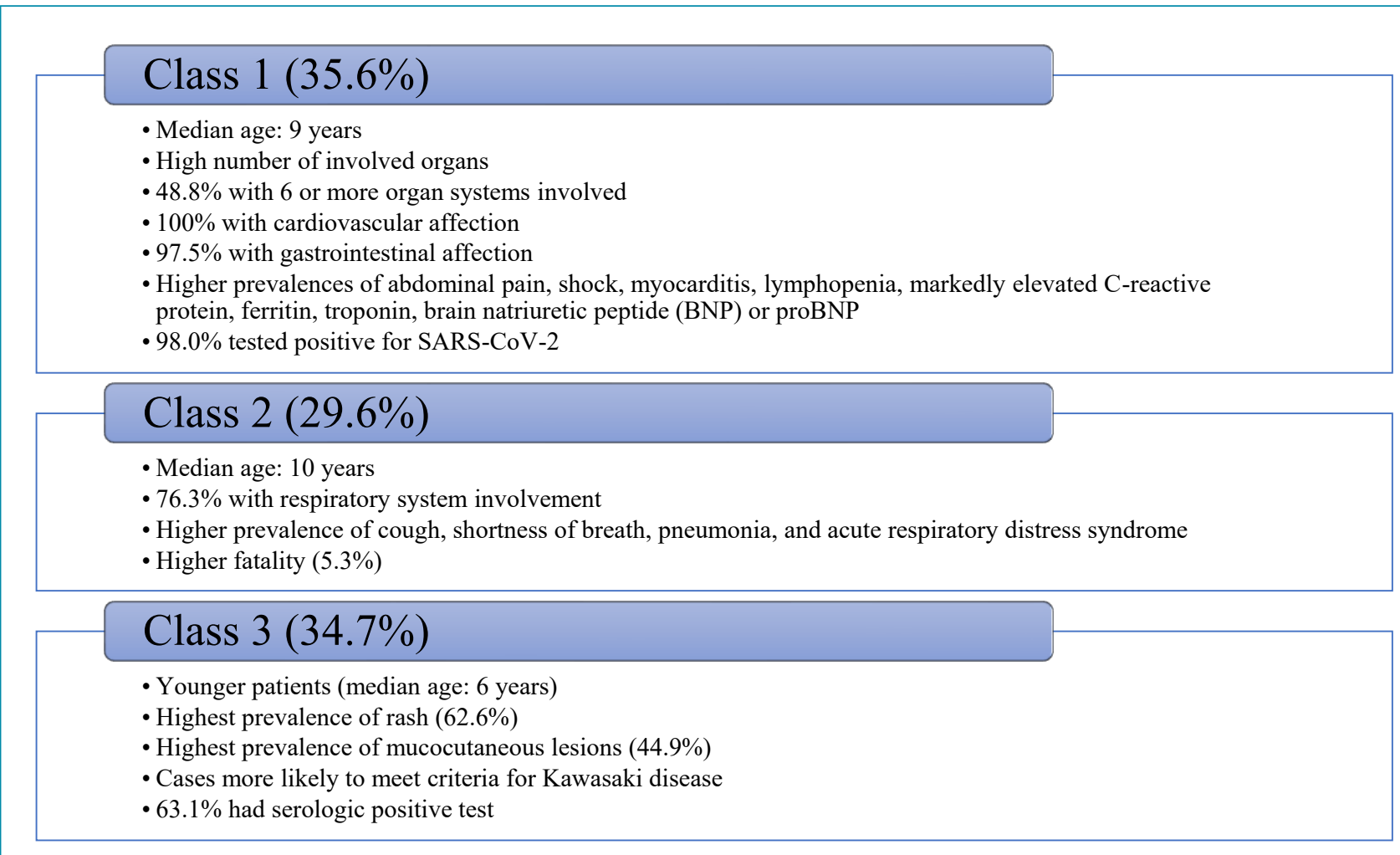

Figure 2. Classification in accordance with the centers for disease control, of 570 patients affected by multisystemic inflammatory syndrome. 
several cases of MIS-C have been identified at hospitals units, so the results are not generalizable beyond the surveillance population. Seen that, in the absence of a comparison group, caution is warranted when interpreting data to infer risk factors for MIS-C.

\section{Treatment}

In the screening of patients with clinical and epidemiological symptoms of COVID-19, initial ambulatory evaluation may be considered. A preliminary laboratory workup is necessary, including complete blood count with differential, liver function tests, urinalysis, electrolytes, erythrocyte sedimentation rate, C-reactive protein, and tests for SARS-CoV-2. Patients who are in good general condition, with stable vital signs, can be followed up on an outpatient basis. Hospital admissions are indicated for patients under investigation for MIS-C with the following symptoms or conditions $s^{13,25}$ :

- Abnormal vital signs (tachycardia, tachypnea);

- Respiratory distress of any severity;

- Neurologic deficits or change in mental status (including subtle manifestations);

- Even mild renal or hepatic injury;

- Severe abdominal pain, uncontrollable vomiting, inability to eat;

- Dehydration;

- KD disease-like features (partial or complete);

- Markedly elevated inflammatory markers;
- Abnormal EKG, BNP, or troponin T;

- Shock;

- Comorbidities (lung diseases, chronic heart diseases, immunodeficiencies, neoplasms, and autoimmune diseases);

- Impossibility of outpatient follow-up.

The need for admission to the intensive care unit will depend on the severity of the signs and symptoms of each patient ${ }^{25}$. As MIS-C is a post-infectious and immune-mediated disease, the need for isolation must be based on positive RT-PCR or serological tests for SARS-CoV-225. During hospitalization, patients under investigation for MIS-C must be followed by a multidisciplinary team, which includes pediatric rheumatologist, cardiologist, immunologist, infectious disease specialist, hematologist, and intensive care pediatrician ${ }^{13,26}$.

In addition to supportive care, treatment consists primarily of addressing the underlying systemic inflammatory state of the syndrome and its consequent complications. Figure 3 shows the basis of current proposed treatment ${ }^{13,25,26}$.

\section{FINAL CONSIDERATIONS}

Since the beginning of the COVID-19 pandemic, much has been discussed and reported in the scientific community. Unlike adults, the vast majority of children with COVID-19 have mild symptoms. However, there are reported cases of children who present conditions related to a hyperinflammatory

- Intravenous immunoglobulin (IVIG) has been used in moderate and severe cases and in patients who present with Kawasaki disease-like features (partial or complete) or even with macrophage activation syndrome. IVIG is also indicated in patients who present with toxic shock syndrome refractory to conventional treatment. The dose is $1-2 \mathrm{~g} / \mathrm{kg}$; a repeated dose of IVIG can be used in refractory cases.

- Methylprednisolone has been used along with IVIG for severe and refractory cases. The initial dose is 10 to $30 \mathrm{mg} / \mathrm{kg} /$ day (from one to three days), followed by $2 \mathrm{mg} / \mathrm{kg} /$ day for another five days, and being tapered in two or three weeks.

- Immunomodulators, such as anakinra, canakinumab, and tocilizumab should be considered in cases with poor response to IVIG and corticosteroids.

- Acetyl salicylic acid (ASA) is recommended for the treatment of embolic phenomena, especially in patients with Kawasaki disease-like features and/or thrombocytosis ( $\geq 450,000 / \mu \mathrm{l})$. The dose is $30-50 \mathrm{mg} / \mathrm{kg} / \mathrm{day}$ and it is started during the active phase of the disease. As soon as the patient remains afebrile for 48 hours, the dose should be reduced ( $3-5 \mathrm{mg} / \mathrm{k} / \mathrm{day}$ ). This dose is maintained until the platelet count is within the normal range and if no coronary abnormalities are observed. Enoxaparin, associated with low doses of ASA, should be used in cases of major coronary artery aneurisms; the use of enoxaparin alone is indicated in cases of ventricular dysfunction (ejection fraction $<35 \%$ ) or documented thrombosis.

- Inotropic support, with vasoactive drugs (dobutamine, milrinone, and epinephrine), may be required in more than $50 \%$ of patients with MIS-C.

- Antibiotics are indicated when secondary bacterial infection is suspected or in cases with shock and sepsis. Ceftriaxone associated with clindamycin has been the most used regimen. In principle, the use of antivirals is not indicated because MIS-C is considered a post-infectious syndrome.

Figure 3. Basis of current proposed treatment for multisystemic inflammatory syndrome in children. 
response, similar to that observed in adults. The full spectrum of MIS-C is not yet clear, as well as it is not clear yet if geographic distribution in North America and Europe reflects a true pattern or if the condition has simply not been recognized elsewhere. Therefore, there is an urgent need to collect standardized data describing clinical presentations, severity, outcomes, and epidemiology ${ }^{21}$. Until further robust data on the etiology of MIS-C is available, pediatricians should be alert to the rapid recognition of these cases, enabling appropriate management in emergency services, hospital wards, and intensive care units (ICUs).

Health professionals must receive information that can assist in the recognition of the MIS-C diagnosis. Common clinical features of MIS-C include fever and other clinical signs, such as findings of rash, conjunctivitis, hands and feet edema, red and / or chapped lips, "strawberry" tongue, myocardial dysfunction, cardiac conduction abnormalities, shock, gastrointestinal symptoms, and lymphadenopathy, as well as neurological changes. However, these findings can occur both in other infectious and in non-infectious diseases. Thus, the diagnostic evaluation must include other differential diagnoses more common in pediatric population and relate clinical presentation to the high prevalence of COVID-19 cases with patient's geographic region. Distinguishing patients with MIS-C from those with acute COVID-19 and other hyperinflammatory conditions is essential for early diagnosis and appropriate treatment.

\section{AUTHORS"CONTRIBUTION}

CANA: Conceptualization, Data Curation, Formal Analysis, Investigation, Methodology, Project Administration, Resources, Supervision, Validation, Visualization, Writing - Original Draft, Writing - Review \&Editing. LADC: Conceptualization, Data Curation, Formal Analysis, Investigation, Methodology, Project Administration Resources, Supervision, Validation, Visualization, Writing - Original Draft, Writing - Review \&Editing. ISF: Formal Analysis, Investigation, Methodology, Validation, Visualization, Writing - Original Draft, Writing - Review \& Editing. IRLC: Validation, Visualization, Writing - Original Draft, Writing - Review \& Editing. AAC: Formal Analysis, Methodology, Validation, Visualization, Writing - Original Draft, Writing - Review \& Editing. FVU: Conceptualization, Formal Analysis, Investigation, Methodology, Validation, Visualization, Writing - Original Draft, Writing - Review \& Editing.

\section{REFERENCES}

1. Word Health Organization. Coronavirus disease (COVID-19). Situation report - 204. Report No: 204. 11 August 2020. Geneva: Word Health Organization; 2020. [cited on Aug. 12, 2020]. Available from: https://www.who.int/docs/defaultsource/coronaviruse/situation-reports/20200811-covid-19sitrep-204.pdf?sfvrsn=1f4383dd_2

2. Hon KL, Leung KKY, Leung AKC, Sridhar S, Qian S, Lee SL, et al. Overview: the history and pediatric perspectives of severe acute respiratory syndromes: novel or just like SARS. Pediatr Pulmonol. 2020;55(7):1584-91. https://doi.org/10.1002/ ppul.24810

3. Panahi L, Amiri M, Pouy S. Clinical characteristics of COVID-19 infection in newborns and pediatrics: a systematic review. Arch Acad Emerg Med. 2020;8(1):e50. PMID:32440661

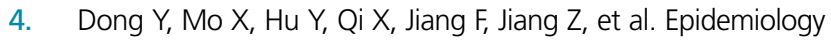
of COVID-19 among children in China. Pediatrics. 2020;145(6):e20200702. https://doi.org/10.1542/peds.2020-0702

5. Nogueira-de-Almeida CA, Del Ciampo LA, Ferraz IS, Del Ciampo IRL, Contini AA, Ued FDV. COVID-19 and obesity in childhood and adolescence: a clinical review. J Pediatr (Rio J). 2020;96(5):546-58. https://doi.org/10.1016/j.jped.2020.07.001

6. Godfred-Cato S, Bryant B, Leung J, Oster ME, Conklin L, Abrams J, et al. COVID-19-Associated multisystem inflammatory syndrome in children - United States, March-July 2020. MMWR Morb Mortal Wkly Rep. 2020 Aug 14;69(32):1074-1080. https://doi.org/10.15585/mmwr.mm6932e2
7. Parri N, Lenge M, Buonsenso D. Children with Covid-19 in pediatric emergency departments in Italy. N Engl J Med. 2020;383(2):187-90. https://doi.org/10.1056/ NEJMc2007617

8. Feldstein LR, Rose EB, Horwitz SM, Collins JP, Newhams $M M$, Son $M B F$, et al. Multisystem inflammatory syndrome in U.S. children and adolescents. N Engl J Med. 2020;383(4):334-46. https://doi.org/10.1056/ NEJMoa2021680

9. Modesti AM, Plewa MC. Kawasaki Disease. 2021. In: StatPearls [Internet]. Treasure Island (FL): StatPearls Publishing; 2021. PMID: 30725848.

10. Diorio C, Henrickson SE, Vella LA, McNerney KO, Chase J, Burudpakdee $C$, et al. Multisystem inflammatory syndrome in children and COVID-19 are distinct presentations of SARS-CoV-2. J Clin Invest. 2020;130(11):5967-75. https:// doi.org/10.1172/JCI140970

11. Ebina-Shibuya $R$, Namkoong H, Shibuya $Y$, Horita N. Multisystem inflammatory syndrome in children (MIS-C) with COVID-19: insights from simultaneous familial Kawasaki disease cases. Int J Infect Dis. 2020;97:371-3. https://doi.org/10.1016/j. ijid.2020.06.014

12. Greene AG, Saleh M, Roseman E, Sinert R. Toxic shock-like syndrome and COVID-19: multisystem inflammatory syndrome in children (MIS-C). Am J Emerg Med. 2020;38(11):2492.e5-6. https://doi.org/10.1016/j.ajem.2020.05.117 
13. Henderson LA, Canna SW, Friedman KG, Gorelik M, Lapidus SK, Bassiri H, et al. American College of Rheumatology clinical guidance for multisystem inflammatory syndrome in children associated with SARS-CoV-2 and hyperinflammation in pediatric COVID-19: Version 2. Arthritis Rheumatol. 2021;73(4):e13-29. https://doi.org/10.1002/art.41616.

14. Miller J, Cantor A, Zachariah P, Ahn D, Martinez M, Margolis KG. Gastrointestinal symptoms as a major presentation component of a novel multisystem inflammatory syndrome in children that is related to coronavirus disease 2019: a single center experience of 44 cases. Gastroenterology. 2020;159(4):1571-4.e2. https://doi.org/10.1053/j. gastro.2020.05.079.

15. Riollano-Cruz M, Akkoyun E, Briceno-Brito E, Kowalsky S, Reed J, Posada R, et al. Multisystem inflammatory syndrome in children related to COVID-19: a New York City experience. J Med Virol. 2021;93(1):424-33. https://doi.org/10.1002/ jmv.26224

16. Stevens JP, Brownell JN, Freeman AJ, Bashaw H. COVID-19associated multisystem inflammatory syndrome in children presenting as acute pancreatitis. J Pediatr Gastroenterol Nutr. 2020;71(5):669-71. https://doi.org/10.1097/ MPG.0000000000002860.

17. Riphagen S, Gomez X, Gonzalez-Martinez C, Wilkinson N, Theocharis P. Hyperinflammatory shock in children during COVID-19 pandemic. Lancet. 2020;395(10237):1607-8. https://doi.org/10.1016/S0140-6736(20)31094-1

18. Toubiana J, Poirault C, Corsia A, Bajolle F, Fourgeaud J, Angoulvant $F$, et al. Kawasaki-like multisystem inflammatory syndrome in children during the covid-19 pandemic in Paris, France: prospective observational study. BMJ. 2020;369:m2094. https://doi.org/10.1136/bmj.m2094

19. Whittaker E, Bamford A, Kenny J, Kaforou M, Jones CE, Shah $P$, et al. Clinical characteristics of 58 children with a pediatric inflammatory multisystem syndrome temporally associated with SARS-CoV-2. JAMA. 2020;324(3):259-69. https://doi. org/10.1001/jama.2020.10369
20. Singh-Grewal D, Lucas R, McCarthy K, Cheng AC, Wood N, Ostring $\mathrm{G}$, et al. Update on the COVID-19-associated inflammatory syndrome in children and adolescents; paediatric inflammatory multisystem syndrome-temporally associated with SARS-CoV-2. J Paediatr Child Health. 2020;56(8):1173-7. https://doi.org/10.1111/jpc.15049

21. World Health Organization. Multisystem inflammatory syndrome in children and adolescents temporally related to COVID-19. Geneva: World Health Organization; 2020. [cited on Aug. 12, 2020]. Available from: https://www.who.int/news-room/ commentaries/detail/multisystem-inflammatory-syndrome-inchildren-and-adolescents-with-covid-19

22. Centers for Disease Control and Prevention. Health departmentreported cases of multisystem inflammatory syndrome in children (MIS-C) in the United States. Atlanta: Centers for Disease Control and Prevention; 2020. [cited on Aug. 12, 2020]. Available from: https://www.cdc.gov/mis-c/cases/index.html

23. MacDonald KL, Osterholm MT, Hedberg CW, Schrock CG, Peterson GF, Jentzen JM, et al. Toxic shock syndrome. A newly recognized complication of influenza and influenzalike illness. JAMA. 1987;257(8):1053-8. https://doi.org/10.1001/jama.257.8.1053

24. Tofte RW, Williams DN. Toxic shock syndrome. Evidence of a broad clinical spectrum. JAMA. 1981;246(19):2163-7. https:// doi.org/10.1001/jama.246.19.2163

25. Sociedade Brasileira de Pediatria. Notificação obrigatória no Ministério da Saúde dos casos de síndrome inflamatória multissistêmica pediátrica (SIM-P) potencialmente associada à COVID-19. Rio de Janeiro: Sociedade Brasileira de Pediatria; 2020. [cited on Aug. 21, 2020]. Available from: https://www.sbp.com. br/imprensa/detalhe/nid/notificacao-obrigatoria-no-ministerioda-saude-dos-casos-de-sindrome-inflamatoria-multissistemicapediatrica-sim-p-potencialmente-associada-a-covid-19/

26. American Academy of Pediatrics. Multisystem inflammatory syndrome in children (MIS-C) interim guidance. Itasca: American Academy of Pediatrics; 2020. [cited on Aug. 14, 2020]. Available from: https://services.aap.org/en/pages/2019-novelcoronavirus-covid-19-infections/clinical-guidance/multisysteminflammatory-syndrome-in-children-mis-c-interim-guidance/ 